\title{
THREE DIFFERENT AGGLOMERATIONS OF BLOOD CELLS IN A CALIROA LIMACINA LARVA
}

BY

\section{G. BARENDRECHT}

Some time ago in our laboratory a number of larvae of Caliroa limacina Retz., the well known slug like sawfly larva of the pear, were fixed in toto and sectioned into complete series, which were coloured with EHRLICH's or Heidenhiain's haematoxylin and counterstained with eosin. Most of these larvae belonged to the last instar but one, i.e., the last instar still feeding and showing the typical mucous covering. The very last instar does not feed any more and lacks the mucous covering, showing the yellow cuticle.

As in many other insects, in these larvae the blood cells during fixation agglutinate in a peculiar way. They constitute in the sections compact cell masses imitating a real tissue, but showing, in our preparations, handly any cell boundaries. Such preparations are, therefore, almost useless for haematological purposes (cf. Rooseboom, Arch. Neerl. Zool. T II, p. 432-559 (1937)). Nevertheless, we met with several striking peculiarities worth while to be recorded.

Among the specimens belonging to the last instar but one, a larva was found that hardly would have reached maturity if it had been allowed to stay alive, Besides harbouring a parasite larva that probably would have done for it, it had the whole body cavity filled with a dense mass of rod shaped bacteria, that undoubtedly were about to kill the larva in a very short time. As it was, however, no organ showed as yet the least trace of disintegration or infirmity, though the whole body, with exception of the gut, was literally stuffed with bacteria.

This larva, moreover, showed a wound, probably originating from the parasite's oviposition, that had been completely closed.

It was in this larva that three very dissimilar types of leucocyte agglomerations were found.

First, we found cell masses occurring in every specimen of these larvae (Fig. I). The nuclei in this type are situated very closely together, the amount of cytoplasm is but small and cell boundaries are hardly to be observed. Granted that the fixation and colouring mentioned above, are not very refined, I do not think it likely that other methods of fixation in toto would have 
revealed greater detail. In our sections these cell masses have a striking resemblance with some synsytial tissue. Within them are a number of irregular clefts, probably due to shrinking during embedding.

These cell masses undoubtedly are artifacts. Of course, it is not possible to make out with certainty when this agglutination happens: whether during fixation or in the course of the embedding process. It is very likely, however, that agglutination occurs simultaneously with fixation, because, when using

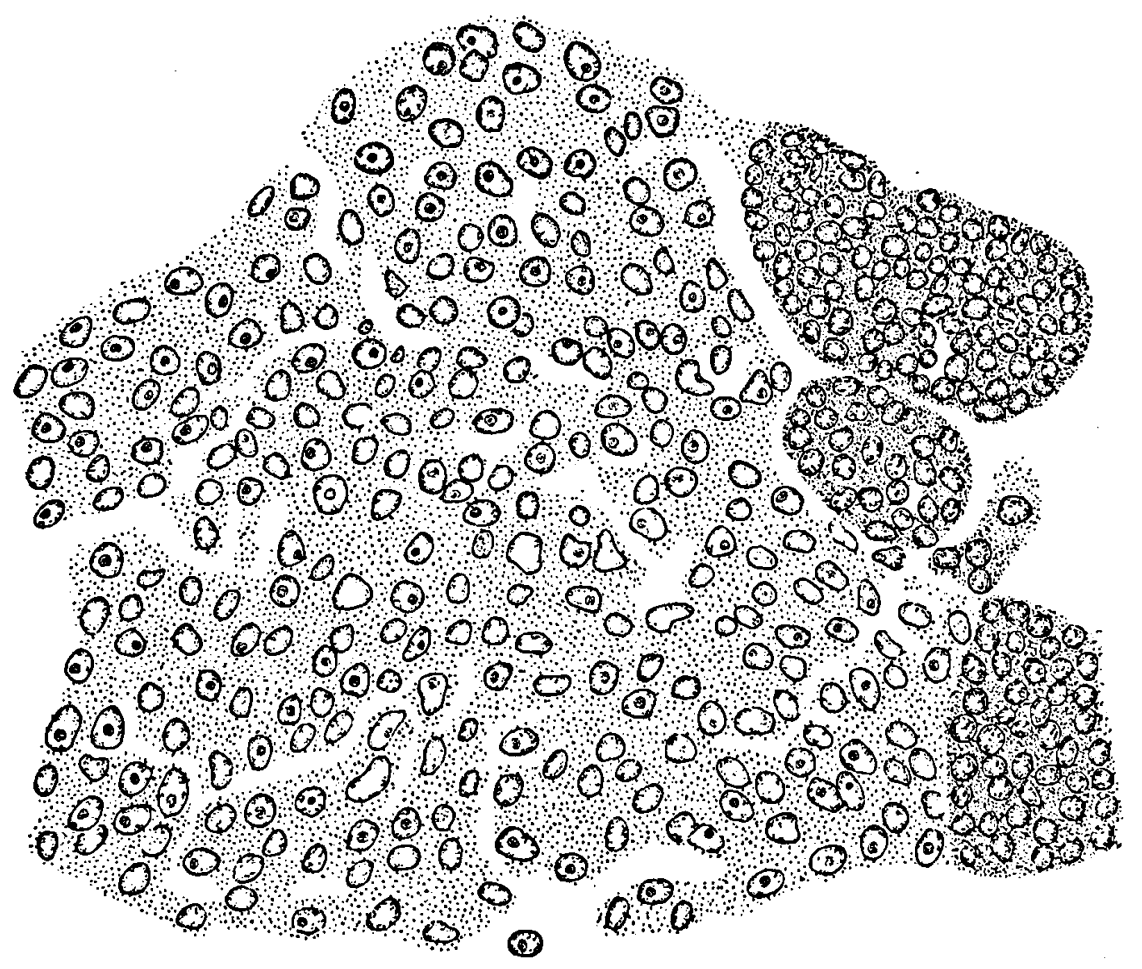

Fig. I. Agglutinated blood cells; to the left, large, little staining cells, to the right, small, strongly staining cells. $\times 450$

Carnoy's mixture, dehydration is almost instantaneous. It is not probable that in the course of the embedding, i.e., during the substitution of the fixative by absolute alcohol, benzene, etc., considerable dislocation of cells takes place. The real cause, however, making the leucocytes agglutinate to such an extent, is not very clear, since this phenomenon may occur to such a high degree in this particular species this is even the rule - that by far the greater part of the leucocytes is to be found in these dense cell masses. Separate cells are only found in the heart and in the pericardial sinus. And these are exactly the cavitities in which the compact cell masses never occur. Mostly they are found in the head and the anterior part of the thorax. This gives rise to the supposition that the cells are drifted together by the last contractions of the 
dorsal vessel. But his would account only for a small percentage of the cells, as none but a very limited part of the leucocytes will pass the heart during the short time in which fixation is completed. Perhaps the contractions of the general body musculature are to be held responsible too.

Another characteristic feature of these cell masses, found in every specimen, is the occurrence of two very different kinds of cells. These are: small, strongly staining cells and larger ones, staining less. Both types keep strictly apart, though agglomerations of the two cell types may be situated closely

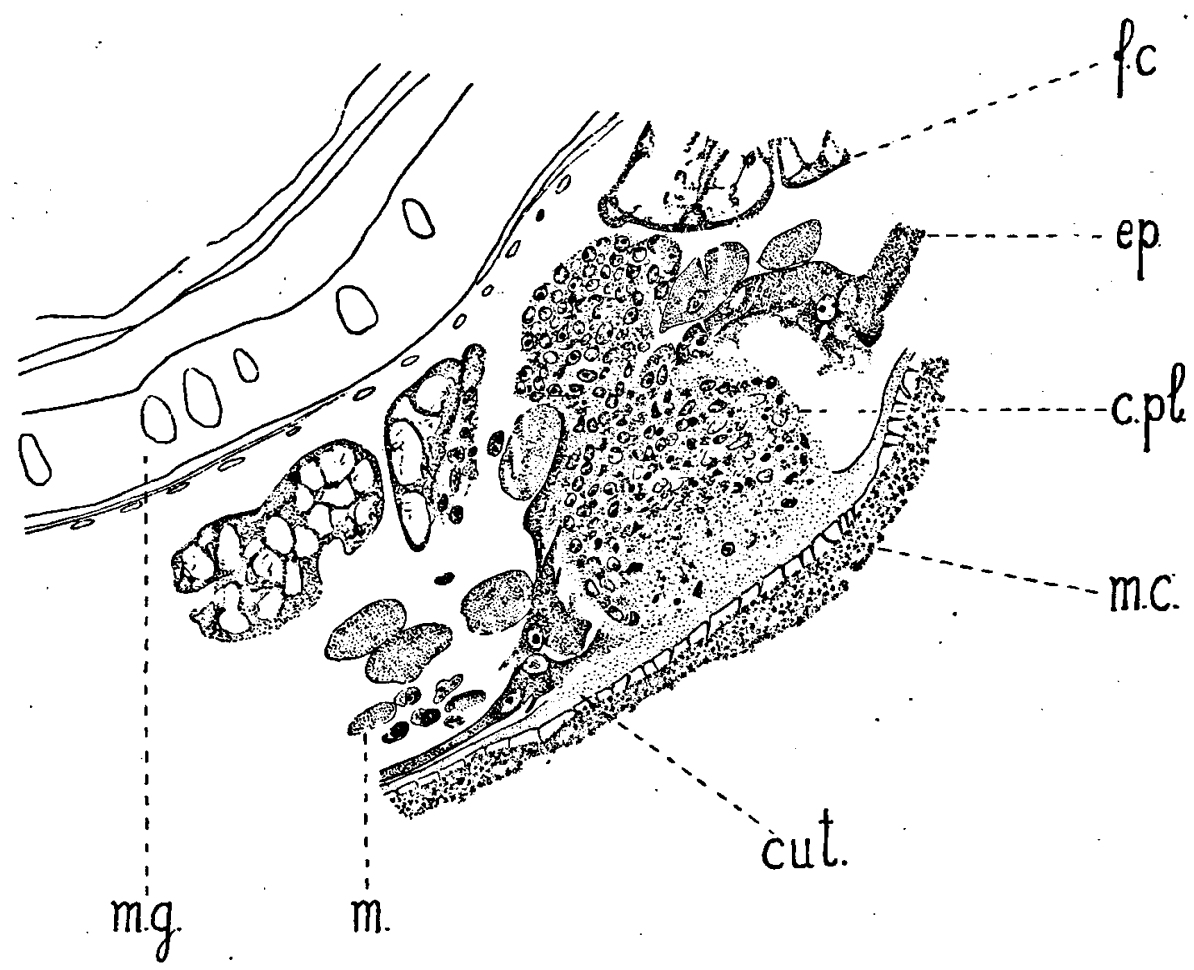

Fig. 2. Central part of wound with cell plug c. pl.; f.c. fat cells; ep. epidermis; m.c. mucous covering; cut. cuticle; m. muscles; m.g. mid gut. $\times 225$

together. This difference in size and staining regards the cytoplasm as well as the nuclei. Although, as mentioned above, the boundaries of the individual cells are not visible, the size of the cell body can be inferred by the distance of the nuclei. In this way, we may take for certain that the small, intensely staining nuclei belong to small cells taking a rather large amount of dye, while the larger nuclei containing less chromophilic substance, are situated in cells of corresponding size.

Of course, the presence of two or more different types of leucocytes is of common occurrence, but it is rather peculiar that in our case the two kinds of cells are keeping so strictly apart. I think, however, that this same fact is 
able to shed some more light on the agglutinations in general. For, it is well known that the several types of leucocytes show characteristic reactions with chenical bodies, f.i. dyes. Now it seems not unlikely that, agglutination being a reaction with the fixative, the different cell types react with a specific velocity to the very acid liquid of CARNOY. In this way, agglutination of one type would be completed before that of the other kind had even started.

An agglutination of blood cells of quite another kind is constituted by the

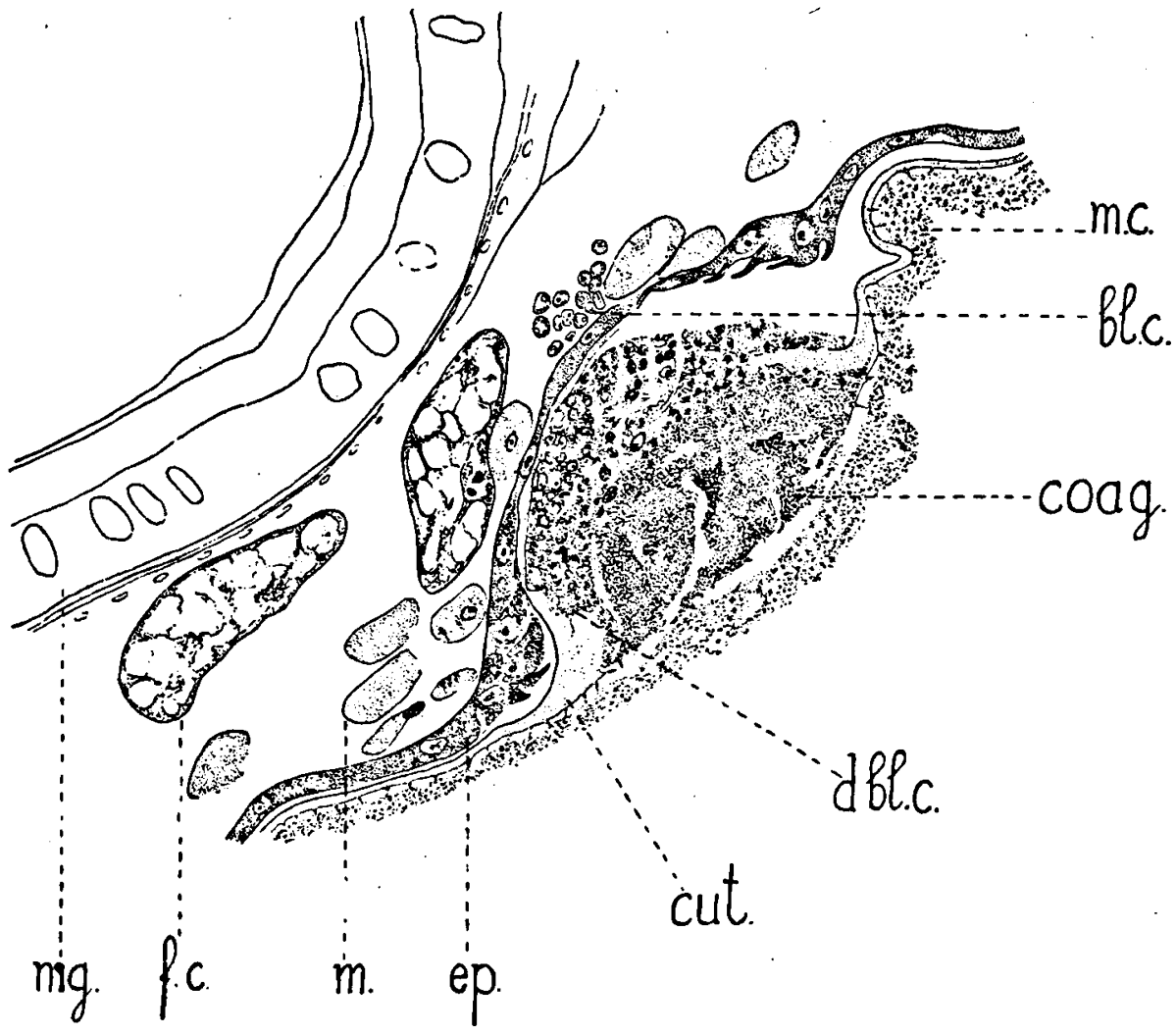

Fig. 3. Lateral part of wound; bl.c. free blood cells; coag. coagulated blood plasm; other lettering see Fig. 2. $\times 225$

cell mass that occludes the wound mentioned above. Fig. 2 shows the gap in the epidermis being locked up by a compact group of blood cells. On the outside these cells are in close contact with the newly formed cuticle, on the inside they bulge into the body cavity. As the epidermis does not yet cover the whole surface of the wound, the modus of wound healing can be studied by comparing sections through the centre of the defect with periferal ones. The epidermal cells along the border of the wound increase considerably in height and eventually form long processes. The cuticle secreted by these cells, is much thicker than that of the general body surface and seems to be shifting 
centripetally over the wound. During this process, the outermost cells of the occluding plug become more or less embedded in the cuticular substance. This configuration could easily be misinterpreted as one might be led to suppose that the cuticle had been secreted by the leucocytes. By far the greater part of these leucocytes gradually degenerate, and so in the peripheral part of the cell mass quite a number of pycnotic and fragmentated nuclei are to be found In the more proximal part of the cell group the normal appearance of the

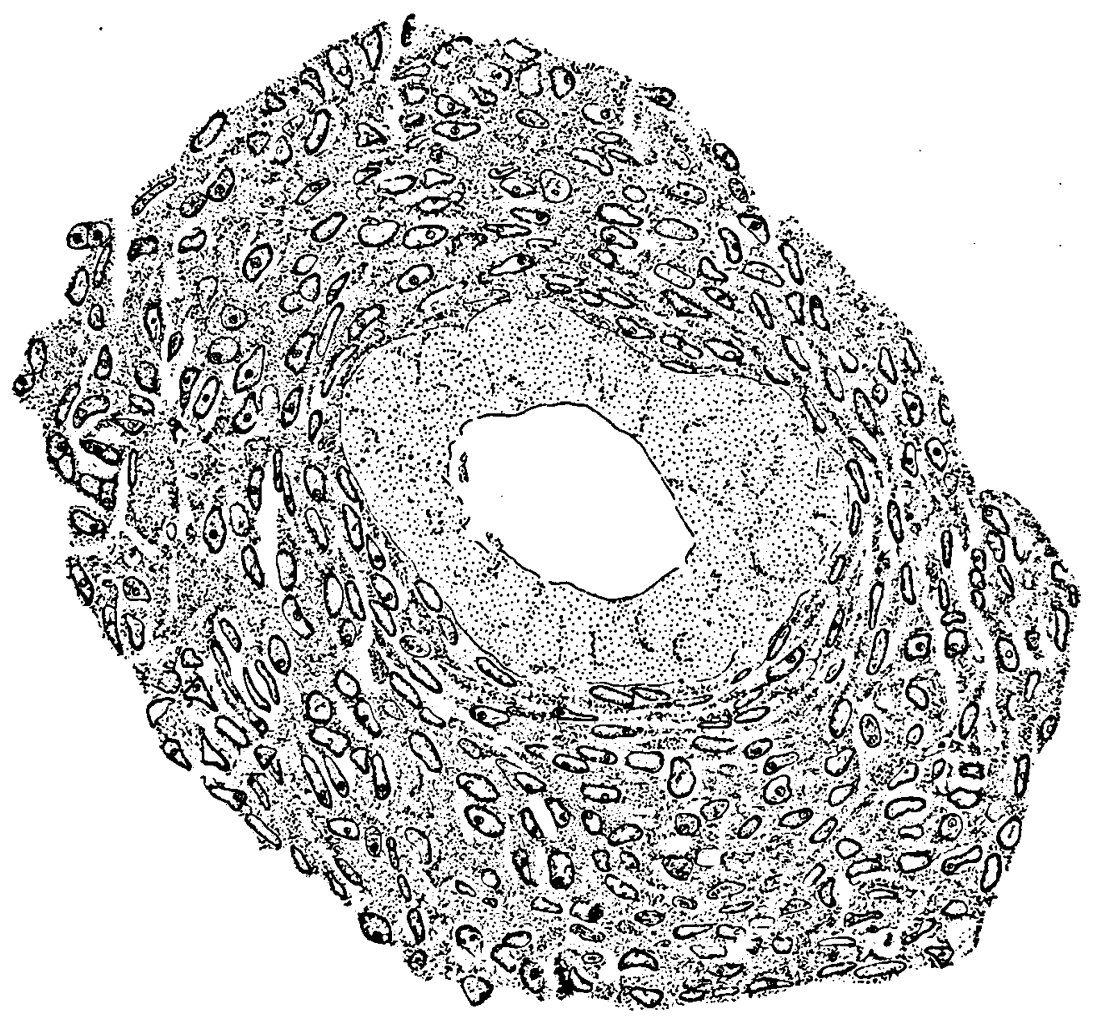

Fig. 4. Blood cells encysting a small corpuscle with a cavity $\times{ }_{450}$

nuclei seems to be preserved for quite a time. Nevertheless, this cell mass, formed in the living larva, exhibits a considerably less homogeneous aspect than those originated by fixation. Fig. 3 shows that eventually the new epidermis shuts off a part of the cell mass, causing, thereby, their total degereration and death.

In this particular agglomeration of blood cells it is not feasible to discern clearly between the two types of cells mentioned abovẹ.

Still another type of cell agglomeration occurs in the shape of cysts including small, yellowish brown corpuscles, of which several are found in this larva (Fig. 4). The nature of these inclusions is not quite clear, but probably they 
originate from the parasite's oviposition. They might be coagulates, formed by the action of the wasp's poison on the blood plasm. In appearance they are small brown particles of various size, irregularly oval and in some cases hollow.

A very characteristic feature of these cysts, mentioned also in literature, is the flattened shape of the innermost cells, resp. nuclei. It is obvious that the whole cell mass has been subject to considerable contraction, flattening forcibly the inner cells.

In this cell mass, formed, like the wound occluding plug, intravitally, two more features are obvious. First, the relatively large size of the cell bodies, and, secondly, the poor staining qualities of the nuclei (the nuclei are situated rather far apart). As a matter of fact most of them seem to be quite empty, i.e., devoid of chromophilic substance. Although in this case too the shape of the nuclei is rather irregular, suggesting some degree of degeneration, pycnotic nuclei are never found. Our Fig. shows that these cells constitute a formidable covering of a small inclusion. This makes the total absence of anything in the nature of a cyst on the parasite larva only the more impressive. The body surface of the parasite larva undoubtedly posesses qualities preventing the host's leucocytes from encysting it. 